of Cambridge) for an examination of the mathematical section of the Portsmouth Collection of Newton manuscripts.

\section{A Lunar Radio Communication Link across the Atlantic}

IN a series of experiments carried out between May 11 and May 14 a lunar radio communication link was successfully established between the Jodrell Bank Experimental Station in Cheshire and the Air Force Cambridge Research Center at Bedford, Massachusetts. A $1-\mathrm{kW}$. frequency-modulated transmitter working on $201.00 \mathrm{Mc} / \mathrm{s}$. was used with the 250 -ft. steerable radio telescope at Jodrell Bank. In the United States an 84-ft. radio telescope was used with receivers of various bandwidths from $\pm 2 \cdot 5$ to $\pm 10 \mathrm{kc} . \mathrm{s}$. Similar receivers were also used on the telescope at Jodrell Bank for monitoring the local lunar returns. The aerial systems were eireularly polarized in order to avoid the deep fading caused by Faraday rotation in the ionosphere. A series of experiments lasting for about $40 \mathrm{hr}$. included the study of the transmission of audio tones up to $15 \mathrm{kc} . / \mathrm{s}$., the transmission of messages by slow Morse, and tests of the intelligibility of speech and quality of music. The tones and Morse were received in the United States without difficulty. Speech as received back at Jodrell Bank was nearly always clear and intelligible, but only occasionally so in America because of the low signal-to-noise ratio of their equipment.

Although trans-Atlantic reception of the lunar radar pulses transmitted from Jodrell Bank was reported in 1958, the recent experiments are believed to be the first to demonstrate the feasibility of a true lunar communication link. The commercial interest in long-distance transmission secure from ionospheric and terrestrial interference will undoubtedly stimulate further developments in this field. Transmitters of somewhat greater power working in the microwave band, where the potentialities of low-noise maser or parametric receivers can be realized, should enable the size of the radio telescopes to be reduced, and at the same time provide sufficient signal-strength to ensure speech intelligibility under all conditions. This work was carried out as part of a joint programme between Jodrell Bank and the Air Force Cambridge Research Center, but the early realization of the successful lunar link was made possible by the interest of Pye Telecommunications, Ltd., which provided the transmitter and receivers.

\section{Creation of the College of Technologists}

THE establishment of the College of Technologists was announced on May 20 by the Governing Body of the National Council for Technological Awards, the chairman of which is Lord Hives. The College will administer the award of Membership of the College of Technologists (M.C.T.) which the National Council proposes to create as a qualification higher than the Diploma in Technology. The College of Technologists will operate within the framework of the National Council for Technological Awards and will be served by the same administrative staff. A Board of Scientific and Industrial Studies is to be responsible for the academic and industrial aspects of the administration of the award. The governing body of the National Council has met as the Court of the College and the following appointments to the Board were made: Sir Arnold Hall, managing director, Bristol Siddeley Engines, Ltd. (chairman);
Mr. A. W. J. Chisholm (head of the Department of Mechanical Engineering, Royal Technical College, Salford) ; Dr. H. O. J. Collier (director of pharmacological research, Parke Davis and Co., Ltd.); Dr. J. W. Cook (vice-chancellor, University of Exeter); Prof. P. V. Danckwerts (professor of chemical engineering science, Imperial College of Science and Technology, London, and Shell professor-elect of chemical engineering, Cambridge); Prof. E. Giffen (professor of civil and mechanical engineering, Queen Mary College, London); Dr. A. A. Griffith (research consultant, Rolls-Royce, Ltd.) ; Sir Stanley Harley (managing director, Coventry Gauge and Tool Co., Ltd.); Prof. A. J. Murphy (principal, Cranfield College of Aeronautics); Mr. P. E. Sleight (head of the Civil Engineering and Building Department, Brighton Technical College); Dr. G. B. B. M. Sutherland (director, National Physical Laboratory); Dr. J. S. Tait (principal, Northampton College of Advanced Technology, London); Dr. J. Topping (principal, Brunel College of Technology) ; Dr. R. C. G. Williams (chief engineer, Philips Electrical, Ltd.).

In addition to the members listed, the Court intends to appoint to the Board one more member of the teaching staff of a College of Advanced Technology. A further statement will be issued as soon as possible giving the details which will be needed for the submission of applications for registration as candidates for membership of the College of Technologists.

\section{Jobs for School Leavers}

INTEResting proposals for dealing with the 'bulge' have been put forward by John Wellens, an industrial training consultant. This year some 900,000 boys and girls will reach the age of fifteen and in 1962 the figure will rise to $1,000,000$. As at present organized, industry and commerce are quite unprepared to absorb the considerable extra number of schoolleavers who owe their existence to increased birthrate during and immediately after the War. The training facilities available for those that can be absorbed are inadequate by the most elementary of standards. To deal with the situation, Wollens suggests that a national industrial training agency should be formed, responsible to the Minister of Labour and National Service, and that the existing Industrial Training Council should act as an advisory body to the Agency ("The Bulge: Its Industrial Impact. A National Plan". John Wellens Organization, 24 Morsley Road, Grasseroft, nr. Oldham. 5s.). Details of the way in which the agency would work are elaborated as well as the main lines it should follow: It is doubtful whether the somewhat impractical proposals will command any wide support.

\section{Government Support for Research in Water Supply}

The Department of Scientific and Industrial Research is to give financial support to the Water. Research Association. The council of the Association has been strengthened by the appointment of Mr. J. E. Beddoe, assistant secretary, Water Division, Ministry of Housing and Local Government, of Dr. B. A. Southgate, director, Water Pollution Research Laboratory, and of Mr. G. A. MeMillan, Department of Scientific and Industrial Research. The Department of Scientifie and Industrial Research has appointed Prof. F. H. Garner (Birmingham) and Mr. C. S. Tanner (Imperial Chemical Industries, Ltd.) as 'visitors'. 